\title{
JOURNAL.RU
}

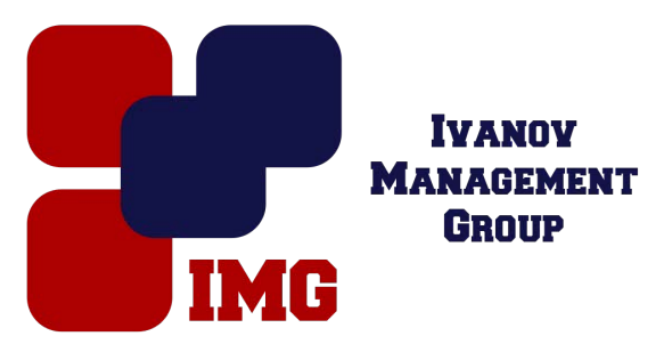

Усикова А.Д.

Государственный Университет Управления Москва, Россия

doi: 10.18411/lj-31-10-2016-1-14

idsp 000001:lj-31-10-2016-1-14

\section{Системный анализ видов и технологий перевозок грузов}

\section{Аннотация}

В исследовательской работе рассмотрены виды транспортных перевозок груза, новые технологии в транспортной логистике.

Ключевые слова: перевозки, транспорт, технологии.

Видытранспортныхперевозокгруза.Перевозки могут производиться как самой компанией, так и сторонней организацией: перевозчиком или экспедитором. Создать собственный автопарк или воспользоваться услугами перевозчика компания решает исходя из затрат в обоих вариантах, надежности перевозчиков и пр. Перевозчики - осуществляют только физическое перемещение груза в пространстве, транспортировку. Экспедиторы- помимо самой перевозки, оказывают ряд дополнительных услуг, таких как: оформление документов на груз, выполнение таможенных формальностей, погрузка/разгрузка, хранение, комплектация и контроль за состоянием груза, страхование и пр., кроме того в процессе перевозок, важную роль играют и вспомогательные логистические партнеры - таможенные брокеры, страховые, охранные и информационные компании, предприятия по грузопереработке и упаковке, грузовые терминалы.

Рассмотрим основные виды перевозок:

- унимодальная (одновидовая) - осуществляется одним видом транспорта и одним транспортным средством, например, 
автомобильным. Применяется - когда заданы начальный и конечный пункты транспортировки без промежуточных операций складирования и грузопереработки;

- смешанная (комбинированная, интермодальная, мультимодальная) осуществляется обычно двумя видами транспорта и более (например: железнодорожным - автомобильным, речным автомобильным, морским - железнодорожным, тубопроводным морским и т.п.).

Существуют различные способы грузоперевозки, и на каждом виде транспорта установлены различные виды грузовых сообщений, отправок и скорости перевозок грузов.

Железнодорожный транспорт. В зависимости от количества груза, принятого по одной накладной, перевозки выполняются мелкими, малотоннажными, повагонными, групповыми и маршрутными отправками.

Мелкой отправкой считается партия груза массой не более 5 т и объемом не более $1 / 3$ вместимости крытого вагона. Малотоннажной отправкой считается партия грузом от 10 до 20 т объемом не более половины вместимости вагона. Для повагонной отправки требуется целый вагон. Групповая отправка - это такое количество груза, для которого требуется более одного вагона, но меньше маршрута. Маршрутной отправкой считается партия груза, предъявляемого к перевозке по одной накладной, для которого необходимо такое количество вагонов, которое соответствует по массе норме поезда.

Автомобильный транспорт. Грузовые автомобильные перевозки различают по следующим правилам:

1) по территориальному признаку - городские, внутрирайонные, междугородние, международные перевозки;

2) способ выполнения: местные - одним автотранспортным предприятием; прямого сообщения - несколькими автотранспортными организациями; смешанного сообщения перевозки двумя или несколькими видами транспорта;

3) по организационному признаку - централизованные и децентрализованные. При централизованных перевозках автотранспортные предприятия выступают организаторами доставки 
грузов получателем и сами осуществляют этот процесс. При децентрализованных перевозках каждый грузополучатель самостоятельно обеспечивает доставку грузов.

Речной транспорт:

1) виды сообщений: внутреннее - в границах одного речного пароходства, прямое - в рамках двух и более пароходств, прямое водное - с участием пароходств, смешанное - с участием других видов транспорта;

2) размер партии - судовая, сборная, мелкая. Судовая партия - груз одного наименования, сдаваемый по одной накладной, а также однородные грузы, сдаваемые по нескольким накладным, следующие в один пункт назначения в количестве, достаточном для полной загрузки отдельного судна. Сборная партия состоит из груза массой выше 20 т в количестве, недостаточном для загрузки целого судна, или достаточного по массе, но адресуемого в разные пункты назначения, что вызывает необходимость отделения одного груза от другого. Мелкой считается партия, предъявляемая к перевозке по одной накладной в количестве, не превышающем 20 т;

3) в зависимости от срочности выделяют доставки с большой скоростью и грузовой скоростью.

Морской транспорт. Классификация морских перевозок предусматривает их деление по видам перевозок, плавания и сообщения:

1) по видам перевозок их разделяют на сухогрузные и наливные;

2) в зависимости от вида плавания морские перевозки делят на малый, большой каботаж и заграничное плавание. Под малым каботажем понимают и заграничное плавание судов в пределах одного или двух смежных морских бассейнов без захода в территориальные воды других государств. Большой каботаж - это плавание судов между портами одной и той же страны, лежащими в разных морских бассейнах.

Новые технологии в транспортной логистике. Логистику, в особенности транспортную логистику, в настоящее время невозможно представить без полноценного применения информационных технологий. Сложно представить 
себе формирование и организацию работы цепей доставки предметов в условиях отсутствия интенсивного оперативного обмена информацией между сторонами транспортного процесса, отсутствия возможностей незамедлительного реагирования на спросы рынка транспортных услуг. В наши дни скорость совершенствования сферы информации довольно-таки высока. В связи с использованием современных технологий и новой техники, разрабатываются все новые информационные связи, представляющие из себя характерную черту большинства процессов, в том числе и транспортной, на национальном и международном уровнях.

Но к сожалению, не каждая компания может предоставить заказчику полное отслеживание товара. Причинами тому, могут быть ограниченность или отсутствие тех или иных технологий. Поскольку, новые технологии всегда дорогостоящие и не каждая компания может позволить их себе. Но есть и технологии, которые уже давно проверенные и внедрены в процесс доставки товара.

Для чего нужна инновация в транспортной логистике? Как она может помочь заказчику? Мировые транспортные корпорации нацеливаются на использование технологичных информационных систем, над созданием которых работают определенные самостоятельные фирмы. Единая технология расчетов, устойчивость экономического положения и стабильность гарантируют этим программным средствам актуальность, уменьшая таким образом их цену. Инновационные технологии заказчику представляют полную информация о товаре, в частности самое главное, это где в данный момент, в данную минуту находится товар. Все это обеспечивают специальное программное обеспечение:

- Система GPS - автоматизированная глобальная спутниковая система, созданная для определения широты и долготы местонахождения транспортного средства.

- Система ГЛОНАСС - предназначена для оперативного навигационно-временного обеспечения неограниченного числа пользователей наземного, морского, воздушного и космического базирования.

- Система ЕspaceCat-информирует пользователя о параметрах перевозимых товаров и схемы их размещения в кузове 
транспортного средства, формируя эти сведения в виде трехмерных графиков.

Современные информационные технологии дают множество возможностей для подготовки и формирования результатов, мониторинга процессов, а также для эффективного анализа технико-экономических проектов. Использование новых информационных технологий, повышает эффективность перевозки товаров. 


\section{Литература}

1. Логистика и управление цепями поставок. Теория и практика. Основы логистики. Аникин Б.А.; Родкина Т.А.; Волочиенко В.А.; Заичкин Н.И.; Межевов А.Д.; Федоров Л.С.; Вайн В.М.; Воронов В.И.; Водянова В.В.; Гапонова М.А.; Ермаков И.А.; Ефимова В.В.; Кравченко М.В.; Серова С.Ю.; Серышев Р.В.; Филиппов Е.Е.; Пузанова И.А.; Учирова М.Ю.; Рудая И.Л. Учебное пособие / Москва, 2014.

2. Логистика: тренинг и практикум. Аникин Б.А., Вайн В.М., Водянова В.В., Воронов В.И., Гапонова М.А., Ермаков И.А., Ефимова В.В., Заичкин Н.И., Кравченко М.В., Пузанова И.А., Родкина Т.А., Серова С.Ю., Серышев Р.В., Федоров Л.С. Учебное пособие / Москва, 2014.

3. Абдулабекова Э. М. Развитие логистики в России. Гуманитарные науки: новые технологии образования. Материалы 10-й Региональной научнопрактической конференции 19-20 мая 2005 г. Махачкала: ИПЦ ДГУ, 2005.

4. Воронов В.И. Методологические основы формирования и развития региональной логистики: Монография. - Владивосток: Изд-во Дальневосточного Университета, 2003. - 316 с.

5. Родкина Т.А. Логистика информационных потоков: состояние и перспективы. Вестник Университета (Государственный университет управления). 2012. №5. С. 144-148.

6. Воронов В.И., Лазарев В.А. Информационные технологии в коммерческой деятельности. Часть 1. Владивосток: Изд-во ВГУЭС, 2000 г. ISBN 5-82240029-9 Присвоен гриф ДВ РУМЦ (УМО) - 104 с.

7. Воронов В.И., Лазарев В.А. Информационные технологии в коммерческой деятельности. Часть 2. (учебное пособие). Владивосток: Изд-во ВГУЭС, 2002 г. ISBN 5-8224-0029-9 Присвоен гриф ДВ РУМЦ (УМО) -112 с.

8. Воронов В.И. Международная логистика. Вестник университета (Государственный университет управления). 2004. Т.700.c.700.

9. Воронов В.И., Воронов А.В. Основные элементы эволюции элементов цепей поставок в международной логистике ЛОГИСТИКА. Проблемы и решения. Международный научно-практический Украинский Журнал. 2013 №, 2. Украина. Харьков. 
10. Воронов В.И., Воронов А.В., Лазарев В.А., Степанов В.Г. Международные аспекты логистики: Учебное пособие. / Владивосток: Изд-во ВГУЭС, 2002. $168 \mathrm{c}$.

11. Воронов В.И., Кривоносов Н.А. Савостьянок Г.Н., Кожанова В.В Инновационные технологии в логистике. Научно-аналитический журнал: «Инновации и инвестиции» № 4, 2015- стр.2-4 